\title{
Augmented Reality (AR) Learning Application Based on the Perspective of Situational Learning: High Efficiency Study of Combination of Virtual and Real
}

\author{
Xiaojun Zhao, Xupeng Li, Ju Wang, Changxiu Shi* \\ School of Education, Hebei University, Baoding, China \\ Email: ^270729292@qq.com
}

How to cite this paper: Zhao, X. J., Li, X. P., Wang, J., \& Shi, C. X. (2020). Augmented Reality (AR) Learning Application Based on the Perspective of Situational Learning: High Efficiency Study of Combination of Virtual and Real. Psychology, 11, 1340-1348.

https://doi.org/10.4236/psych.2020.119086

Received: September 1, 2020

Accepted: September 19, 2020

Published: September 22, 2020

Copyright $\odot 2020$ by author(s) and Scientific Research Publishing Inc. This work is licensed under the Creative Commons Attribution International License (CC BY 4.0).

http://creativecommons.org/licenses/by/4.0/

\begin{abstract}
Augmented reality psychology refers to the application of engineering and other technologies to achieve the superposition of virtual information and the real psychological world. The actual psychological environment and the virtual environment are synchronized in real time in the same spatial relationship. Augmented reality learning is increasingly commonly used in educational psychology. Augmented reality learning is mainly based on constructivism, situational cognition, connectionism, independent learning and physical cognition, etc. It is reflected in the teaching and learning psychology of mental skills, motor skills, cognitive strategies and instructional design of primary and secondary school students. How does augmented reality as a technical means fully integrate with education and teaching psychology? This will grow up to be an important aspect for primary and secondary school teachers and researchers to consider their strengths and challenges.
\end{abstract}

\section{Keywords}

Augmented Reality, Augmented Reality Learning,

Augmented Reality Psychology, Teaching and Learning Psychology

\section{Introduction}

Augmented Reality (AR) is an emerging computer technology based on modern human-computer interaction, intelligent sensing, artificial intelligence, etc. It is a new technology derived from Virtual Reality (VR) technology, but there are a lot of differences between them. The concept of AR in the true sense comes from Boeing's Tom Caudell, etc. Using this technology, 3D virtual objects generated 
by computer, system prompt information and objective scene information can be superimposed on people or objects in real scenes, which can increase and enrich users' psychological perception of the real world. Nowadays, under the background of the Internet plus era, the range of AR applications is becoming wider and wider, from marketing to military, conference and exhibition, etc. This technology is more and more closely integrated with intelligent technologies such as big data and mobile learning, and it is also getting closer to education and other fields. In order to cater to diversified teaching methods, new learning methods combined with technology and educational philosophy of pursuing innovation, the application of $\mathrm{AR}$ in education has attracted more attention, which is mainly reflected in the aspects of teaching psychology such as mental skills, instructional designs and motor skills, as well as the aspects of learning psychology based on cognitive strategies.

Traditional knowledge learning mainly takes knowledge imparting as the value orientation and repetitive training as the main teaching method. AR is applied in the field of education, using context as a bridge to connect the classroom and reality, to change passive into active and to transform abstract into image. The gradual application of augmented reality technology (AR) in the field of education supports students' autonomous and collaborative situational learning methods. This "situational turn" has become an important background of learning science. Situational learning and constructivism theory constitute the supporting theories of learning environment design. According to the perspective of situational learning theory, context is the foundation of learning. If learning is separated from the real situation (environment), there is no need to exist. Learning occurs in activities in the social environment. It puts forward the view that "learning is a legitimate marginal participation", which challenges the dominant position of the view of cognitive information processing, and emphasizes putting individual cognition and learning "in a larger physical and social context" (David, 2002).

\section{Overview of Augmented Reality (AR) Learning}

The core of situational learning in school context is to promote the connection between learning and the real world, and restore realistic situations as the core problem, so that the learning process is related to students themselves and the social environment (Lee \& Butler, 2003). In recent years, in domestic and foreign research, there are many application cases about AR learning. According to the data, many of the target populations of AR application experiments are concentrated in the compulsory education (primary and junior high school) stage (31.6\%), among which the use of AR in infant stage (7.9\%) is restricted by their own conditions (Yu, Li, \& Liu, 2017). However, no matter which stages of education are concentrated, AR technology is mainly applied to the two parts of learning psychology aimed at exploring the rules of learning process and teaching psychology aimed at exploring students' classroom learning. The teaching setting of "bubble planet" fully considers the creation of learning environment and the interesting image of learning content (Chen \& Wan, 2017). In cognitive 
processing, attitude and interest affect the attention and coding of information in information processing system. At the same time, learners interact with the character through AR in the game to mobilize multiple senses and personally participate in the task. This retelling strategy can effectively establish information in long-term memory. Teaching settings need to fully consider the characteristics of learners' cognitive development. The adaptive learning content and the cognitive strategy of active participation, combined with the characteristics of the visualization and sensory experience of AR technology, improve learners' participation. A research demonstrated the "traffic safety" situation created by AR technology, taking the development of students and the interaction between teachers and students as the main effect, and used the detection materials to test the cognition, social development and teacher-student interaction of the experimental group and the control group respectively. The problem education situation of the combination of virtuality and reality constructed by augmented reality ensures the continuity and dynamics of the acquisition of learning situation information. The study found that AR learning has a positive effect on the improvement of short-term learning interest, effective communication between teachers and students, or long-term social development. Secondly, the emergence of AR first solves the problem that the teaching environment is too simple and single. Various experimental space situations can be made into AR content through computer coding and widely used in classrooms or laboratories. In this context based learning process, students will have a good interaction between the knowledge hidden in the behavior mode and the situation. Thirdly, while breaking the physical limitations, it can also break the space constraints in real time. Through AR simulation, a learning scene that integrates virtuality and reality can be constructed, allowing students to personally participate in the interaction of some content that cannot be presented in the real environment. Previous researches take the physics classroom experiments in middle school teaching as examples, such as simple pendulum, Newton's first and second laws experiments to simulate situations (Cai, Song, \& Tang, 2011). Learners can intuitively feel the various experimental scenes described in classroom teaching through AR equipment. In the process of the experiment, the virtual three-dimensional information makes the schema structure which cannot be touched only by abstract ability become more visualized and understandable. With the help of real-time feedback of experimental information and good interactive technology, this kind of research constructs a more effective learning stereotype in students' minds. The real-time perception and tracking of the ever-changing learning situation can provide situational learning resources for learners and enhance students' sense of control over learning. In this process, the teaching problem is transformed into the student's experience of space, and at the same time, the logical problem is described in a virtual way to realize the perceptual goal of spatial learning. Operational activities are expanded, merged, and finally automated at the language level, and the entire practice mode is transformed internally, which is conducive to the flexibility of learning skills. 
AR technology has become a springboard for the rapid development of "realistic" situations. Under the guidance of situational learning theory, learning is transferred from traditional classroom to specific situation, and supports situational learning with the characteristics of mobile AR to diversify learning forms. Learners use smart devices as auxiliary tools to complete knowledge construction through inspection, verification, collaboration, interaction and other flexible ways. The combination of mobile devices and AR technology not only makes learners more interested in learning and more willing to explore actively, but also provides teachers with flexible and diverse teaching methods and teaching strategies.

\section{Educational Psychological Theory Supporting Background of Augmented Reality (AR) Learning}

\subsection{Educational Psychological Theories of AR Learning}

The Kinect somatosensory interaction technology used in the English class through the creation of virtual interactive situations and role-playing activities, not only enhances students' interest in learning, but also enhances the sense of immersion in learning (Liao, 2014). Choosing and playing different roles is an important way for students to recognize and solve problems from different perspectives (situations), and the mixed use of new AR technologies will allow role players to have a more realistic experience in it. From the researches of AR technology in the past 20 years, in addition to traditional role theory, constructivism theory and humanistic theory, AR learning researches at home and abroad are mainly based on the following educational psychological theories.

\subsubsection{Connectivism Learning Theory}

Connectivism learning theory has digital characteristics of modern society (different from the early behaviorism and cognitivism education psychology schools), and knowledge organization and networked learning have become its core concepts. Connectivism holds that the network is a learning platform, and the learning process promotes a new network. At the same time, the application of AR technology can effectively combine space, technology, people and knowledge systems, so that any node can maintain the status of circulation, transformation and connection at any time. AR technology plays a role of network in teaching.

\subsubsection{Situated Cognition Theory}

Situated cognition theory holds that knowledge is effective only when it is acquired and used in real life situations. It emphasizes the interaction between knowledge and situation. Learners can construct and improve their knowledge system in real learning situations through autonomous or cooperative learning. All individuals together constitute the situation in which they live, and at the same time, the situation affects the individual's actions and thoughts. According to the theory of situated cognition, learning is not an individual behavior and isolated individual activity in the mind, but a legitimate marginal participation 
in the community of practice. AR technology superimposes virtual information into real learning situations, so that learners are immersed in this combination of virtual and real learning situations and have the authenticity of cognitive activities. Learners can intuitively feel the image of learning things and increase the interaction with the surrounding things. Under this mutual influence, learners and learning situations are constantly changing, so as to deeply understand and master the learning content.

\subsubsection{Autonomous Learning Theory}

This theory emphasizes the importance of students' independent exploration and active construction of knowledge. Through the help of feedback information, students constantly deepen the understanding of objective things and the ability to solve problems (exploratory). Combined with AR technology, through situational awareness, it can enhance the real experience of learning environment (constructive), and at the same time, learners get a sense of learning pleasure and control.

\subsection{Research Perspectives of AR Learning Research}

\subsubsection{Sensory Integration Perspective}

Because of the sense of presence they feel, the processing of human's sense input of virtual object and real object will improve students' intuitive cognition of environment, enhance their real subjective feeling of environment, and cultivate alternative learning ability, which will further lead to profound changes in memory, speech, thinking and behavior reaction.

\subsubsection{Informed Interaction Perspective}

Using AR technology to create a relaxed learning atmosphere for senior high school students can stimulate their active interest in learning. The real learning environment affects students' scientific cognition and changes their learning styles.

\subsubsection{Theory of Mind Perspective}

Theory of mind is a series of abilities that an individual can deduce mental state to other individuals and establish a conscious and goal-oriented framework to understand the behavior of others. The infiltrating feature of AR makes people feel immersive and participate in it with real self role. AR can be called "the most perfect situational learning scaffold".

\subsubsection{Embodied Perspective}

Embodied cognition causes people to think about embodied education, and embodied education environment is the prerequisite of embodied education. Under the guidance of AR technology, the blended learning situation which integrates the physical environment and the network virtual environment just meets the basic requirements of embodied learning environment. Embodied learning environment is related to daily life experience, which improves the authenticity of learners' participation in the real environment. In this learning situation, learn- 
ers can participate in the interaction of the changing surrounding environment through body movements to complete the task of learning knowledge and understanding principles. The design of learning environment under augmented reality technology is mostly based on the perception of body organs, changes and movements of limbs to understand the theoretical meanings.

\section{The Advantages and Prospects of Augmented Reality (AR) Learning in the Psychological Applications of Education and Teaching}

AR technology has been widely used both in terms of teaching psychology and students' psychology, but there are still many problems: First, many researchers blindly pursue technical means of AR learning, rarely combine with educational and teaching concepts, and there is a lack of research on educational and psychological mechanisms. Second, the concept of using AR teaching of front-line teachers is weak. AR course resources are not easy to obtain, and the utilization rate is low. At this stage, the individual differences of learners are not fully considered. At the same time, whether from the perspective of teachers or learners, AR technology in the teaching design level, such as creating a real situation, has become an important grasp of the overall advantages of AR learning in teaching. Although there are many problems, the advantages of AR learning are obvious.

Situated cognition theory holds that knowledge comes from real life situations. Only when knowledge is acquired and used in real life situations can it be effective. It emphasizes the interaction between knowledge and situation. Learners can construct and improve their knowledge system in real learning situations through autonomous or cooperative learning. All individuals together constitute the situation in which they live, and at the same time, the situation affects the individual's actions and thoughts. Situated cognition theory holds that the fundamental feature of learning is situational. Students adapt to the environment by acting on the environment. The virtual situation and the combination of virtual situation and actual situation provide good learners with effective learning conditions. In the process of situations interaction, individuals also get the ability of effective activities, resulting in learning transfer. Augmented reality (in the AR environment, the positive emotional experience is activated) technology by superimposing virtual information into the real learning situation, immersed in the learning situation of this combination of virtuality and reality, learners can intuitively feel the image of learning things and increase the interaction with the surrounding things. Under this mutual influence, learners and learning situations are constantly changing, so as to deeply understand and master the learning content.

Based on NETP 2010, some researchers put forward the "technology-enabled learning" model for the first time. The "technology-enabled learning" model emphasizes technical support and learner-centered concepts. The support of AR technology not only enables students to truly enter realistic situations, play real roles, carry out related activities, and realize the free conversion of multiple 
learning methods, but also enables teachers to externalize implicit knowledge and improve teaching effects. It not only empowers students' situational learning, but also empowers teachers' situational teaching (Wang, Cheng, \& Gao, 2018). Although AR is a newly emerging technology, the time of being integrated with education and teaching is also very short, but due to its high coincidence with educational psychological theories, such as embodied cognition and situated cognition, as well as the characteristics of interaction and combination of virtuality and reality of augmented reality technology, the application of AR technology has been paid more and more attention in the field of education at home and abroad. Basically, there are AR technology applications in each education stage, but the advantages of AR technology are not limited to these.

\subsection{Seamless Integration of Learning Space}

AR learning can allow learners to use image-based tracking technology to ubiquitously and seamlessly switch between virtual and real environments, generating a student-centered seamless integrated learning space to promote seamless learning. Combined with the application examples of seamless learning space provided by Xiao Jun and others, future research will help realize the optimal integration of learners and AR technology, and promote the transformation of existing learning paradigms (Siegel, 1981). At the same time, situational learning theory puts forward a new position of learning situation. It thinks that in the process of individual learning, not only should they interact with the social and cultural environment, but also should interact with the physical environment in real time. This kind of "realistic situation" can help learners acquire knowledge and skills more deeply (Wang, 2002).

\subsection{Active Construction of Large-Scale Space}

The establishment of large-scale space has a good effect on the improvement of the ecological validity of learning research. Adopting a change in learning methods to promote students' autonomous learning will be of great benefit to the improvement of students' academic mood. AR learning is a useful attempt. The research of augmented reality learning belongs to large-scale space research (Xiao et al., 2015; Acredolo, 1981; You \& Zhao, 2015). AR learning focuses on learners' cognition, and constructs cognitive strategies in different learning environments. This strategy enables information to be effectively accessed, retold, processed and organized in memory. For example, the bubble planet game design designed for children is a good representative (Lee \& Butler, 2003). In cognitive processing, attitude and interest affect the attention and coding of information in information processing system. At the same time, learners interact with the character through AR in the game to mobilize multiple senses and personally participate in the task. This retelling strategy can effectively establish information in long-term memory. The interesting learning content and the cognitive strategies of active participation in augmented reality learning, combined with the characteristics of the visualization and sensory experience of augmented 
reality technology, have improved learners' participation. Augmented reality learning aims to improve students' sense of control and value evaluation of the learning process through the learning environment constructed by augmented reality technology, and use the construction of large-scale space to adjust the structure of learning objectives.

\subsection{Maximizing the Utility of Immersive Learning and Mobile Learning}

In the state of immersion, learners will feel that their behaviors are meaningful, and can actively control their consciousness to focus their consciousness on a certain goal. The experiential learning environment based on AR technology creates a high sense of immersion for students, enriches natural interaction methods, and provides timely feedback and targeted guidance to stimulate their internal motivation for learning. Experiential learning uses situational display as the main information presentation method, which has the authenticity of cognitive activities. This learning situation will help the construction of knowledge. At the same time, the combination of $\mathrm{AR}$ and mobile devices makes the research small and mobile, so that users can get rid of the limitations of the environment on the equipment, increase innovation opportunities, promote the improvement of students' creativity, and also provide teachers with flexible and diverse teaching strategies.

\subsection{Multi Ability Participation of Thinking, Emotion and Behavior Supported by Digital Classroom}

AR learning provides a digital classroom learning atmosphere, and is conducive to multiple participation of thinking, emotion and behavior. AR teaching helps to optimize learning situation, develop situational curriculum and implement situational teaching. This mode can effectively stimulate students' thinking flexibility and increase the interaction between teachers and students. Students can participate in learning from the aspects of thinking, behavior and emotion. AR learning is an important new force to overcome the shortcomings of traditional online learning. With the increasing demand for online learning, AR learning is bound to become an important way of learning in modern society.

\section{Acknowledgements}

This study was supported from The National General Project of the Planning Subject for the National Education Sciences in 2020 "The Research on Cognitive and Emotional Mechanism of Augmented Reality (AR) Multimedia Learning and Its Promotion to Primary School Students' Efficient Learning" (Project approval number:BBA200031).

\section{Conflicts of Interest}

The authors declare no conflicts of interest regarding the publication of this paper. 


\section{References}

Acredolo, L. P. (1981). Small- and Large-Scale Spatial Concepts in Infancy and Childhood. New York: Academic Press.

Cai, S., Song, Q., \& Tang, Y. (2011). Architecture and Practice of Augmented Reality Learning Environment. China Educational Technology, No. 8, 114-119.

Chen, X. D., \& Wan, Y. (2017). Development and Application of Augmented Reality Educational Game-Taking "Bubble Planet" as an Example. China Educational Technology, No. 3, 24-30.

David, H. J. (2002). Theoretical Foundations of Learning Environment. Shanghai: East China Normal University Press.

Lee, H. S., \& Butler, N. (2003). Making Authentic Science Accessible to Students. International Journal of Science Education, 25, 923-948. https://doi.org/10.1080/09500690305023

Liao, H. J. (2014). Research on Constructing Virtual Teaching Situation in English Classroom by Using Kinect. Modern Educational Technology, 24, 64-70.

Siegel, A. W. (1981). Externalization of Cognitive Maps by Children and Adults: In Search of Ways to Ask Better Questions. New York: Academic Press.

Wang, M., Cheng, J. M., \& Gao, S. L. (2018). Use Technology to Empower Situational Learning. Modern Educational Technology, 28, 13-19.

Wang, W. J. (2002). A Review of Research on Situational Cognition and Learning Theory. Global Education, 31, 51-55.

Xiao, J., Jiang, B. Q, Xu, Z., \& Yu, Y. (2015). Creation and Application of Seamless Learning Space under Ubiquitous Learning Concept. Modern Distance Education Research, No. 6, 96-103.

You, X. Q., \& Zhao, X. J. (2015). Prospect of SNARC Effect Based on Augmented Reality and ERPs Architecture. Journal of Psychological Science, 38, 258-262.

Yu, C. B., Li, Q., \& Liu, Y. (2017). Current Situation and Development Trend of Educational Research on Augmented Reality (AR) Technology—Based on 2011-2016 Chinese and English Journal Literature Analysis. Distance Education Magazine, 35, 104-112. 